\title{
An Overview of Current Library Support for Readers with Special Needs
}

\section{Katherine Read}

$\underline{\text { June } 2003}$

\section{Introduction}

The Social Model of Disability sees "disabled people disabled by physical, organisational and/or attitudinal/behavioural barriers in society. For instance it is not an inability to climb stairs that excludes wheelchair users from accessing the different floors of a library but the fact that a lift or ramp is not provided in the first place" 1

The Disability Discrimination Act 1995 (DDA) included an exemption for Higher Education Institutions. The Special Education and Disability Act (SENDA) 2001 has now become part IV of the DDA and the original exemption has been repealed. This has had important implications for all library and information services.

With a view to improving the facilities for readers with special needs at IALS, I undertook an overview of the services offered at a selection of twelve University library/information services mostly within the M25 area. The purpose of this article is to summarise the findings of this brief survey in order to paint a picture of the general level of service currently available. The information presented has mostly been obtained from the web sites of the institutions involved, which will not be identified in the report. In some cases the institutions have multiple sites and the survey has concentrated on a main site library as a sample. The focus here is on a number of key areas, namely physical access, client support, special equipment, photocopying support and extended loans.

\section{Part 1 : Background}

\section{What counts as a disability?}

In the DDA 1995, it is stated that an adult or child is disabled " if he or she has a physical or mental impairment that has a substantial and long term adverse effect on his ability to carry out 'normal' day to day activities" 2

\footnotetext{
${ }^{1}$ Jones, Sandra. Recommendations to improve accessibility for disabled users in academic libraries. Bristol CLAUD (CLAUD = Consortium of librarians in higher education networking to improve access for users with disabilities in South and Southwest England) 2002, p.6

${ }^{2}$ Disability Discrimination Act 1995 s. 1
} 


\section{A responsible body discriminates against a disabled person if}

- "For a reason which relates to his disability, it treats him less favourably than it treats or would treat others to whom that reason does not or would not apply" 3

- It fails to make a reasonable adjustment.

\section{Part 2: Overview}

\section{$\underline{\text { Access }}$}

This can be divided into two sections, firstly access to the building and secondly availability of collections within the Library or Information Unit. Access to the building is generally good. A combination of ramps and lifts enables most students to enter. The most severe restrictions within the building were due to building work being undertaken at one college. The lifts were out of order and readers unable to use the stairs had no access to the library before $11 \mathrm{am}$ and after 9pm Monday to Friday. It was unclear when the work would be completed. Within libraries the main problems are concerned with reaching materials without assistance. In two libraries, wheelchair users have no access to whole collections particularly journals. A third library has similar problems but is currently planning improvements. Another library has the difficulty of very high shelves. Although book retrieval services are offered, the lack of access means that users are not able to browse in the same way as others users.

\section{Staff Support/Services}

The most common support services offered within the library were as follows:

- Book retrieval. Most institutions had at least an ad hoc arrangement to retrieve volumes in advance. One places a limit of 15 items per week. One requires a half day's notice. Two require $24 \mathrm{hrs}$ notice for support from a member of staff. One offers an e-mail retrieval service ( 2 days notice). Two provide support through an official assistant employed by the college. Two others provide some help but do not specify a period of notice or give details of the service offered.

- Remote document/book supply: This was generally more limited. One college provides a special service for students not eligible for DSA help. This includes postal loans and photocopies and database searches. Two others allow students to request articles from home. In one case, these items are scanned electronically and book loans are also possible.

\footnotetext{
${ }^{3}$ Disability Discrimination Act 1995 s. 28R
} 
- Support assistants: It seems very reasonable to allow students to bring a personal assistant with them and to allow the assistant to borrow books on behalf of the student. Six colleges definitely had a permanent arrangement to allow readers to bring an assistant in and one of these allowed borrowing rights. Others may have a similar arrangement but did not advertise it. One specified that 24 hours notice was required whenever an assistant wanted access. This seems unnecessarily restrictive.

- Remote access: Only one college highlights remote access to online services, probably because these are services available to everyone, not specifically to disabled students. It offers online access to over 2000 journals, the CD-Rom network, various databases, exam papers and electronic readings.

- Specific Contact within library: One college has a special e-mail contact for users with special needs. One has disability support coordinators on each site, though not necessarily based within the library. Another appoints members of staff (not library staff) to support individual students. In one case there is an apparently very active support service, which employs students as support assistants. These assistants have a wide variety of duties, which include assistance in the library setting.

\section{Special Equipment}

This section shows the widest variety in the type and level of assistance currently available. The following themes occur most frequently.

- Hardware/software : Most institutions provide some special facilities but these vary enormously. The main facilities featured included a video magnifier, large text display machine with voice synthesiser, JAWS screen reading and MAGIC text enlarging software, KURZWEILL scanning software with output to a laser printer or Braille embosser and MAGNILINK (magnifies and changes colour of text). Two of the colleges seemed to offer very little in the way of special equipment while two others seemed particularly advanced. One has a separate learning support unit. The other has a special needs area with assistive computer provision on each campus. The software is suited to students with physical disabilities and sight impairment as well as dyslexia. The centre was developed on advice from the CCPD (Computer Centre for People with Disabilities). This centre is based at the University of Westminster.

- Large print leaflets: Two colleges mention the provision of large print leaflets. One of these also offers the use of coloured paper but requires a week's notice. Another states that library information is available in a variety of formats.

- Induction loops: One college has a multilevel issue/enquiry desk with induction loops and other assistive technology. Another has loops in lecture theatres. 


\section{Photocopying Support}

This can be divided into two parts, reduced cost copying and assistance with making copies.

- Reduced cost: One college stands out as the only institution, which provides free photocopying to all students who have a referral from the disability adviser. Another provides this for students who are not eligible for DSA financial support. Others supply receipts as needed or refer students to SKILL (Organisation for students with disabilities) for financial assistance.

- Assistance with photocopying : The level of assistance provided varies quite considerably. Three colleges are willing to make copies for students and send them out either by post or electronically. Two colleges rely upon support assistants arranged by the college to provide this assistance on site. Three other colleges have a more ad hoc arrangement. One college states that a student must usually arrange their own support but staff may be able to assist. One college states specifically on the web site that library staff cannot help with copying. Readers must bring their own assistants in when necessary.

\section{Extended Loans}

Services provided here were fairly similar. Two libraries are excluded from this category because they are for reference only.

- Extended loans: Most colleges allowed a double loan period. Eg. Two weeks instead of one or 48 hours instead of 24 hours in case of the more heavily used texts. Three colleges allow unlimited remote renewal provided that no other reader has placed a reservation.

- Postal loans: Two colleges offer postal loans.

\section{Conclusion}

Each of the categories considered here, with the possible exception of the extended loans service, shows quite wide differences in the level of provision offered. There were, of course, limitations in this study, which relied largely on information provided on the web sites. It was not possible, within the time available, to contact every college and to verify every detail presented on the web sites observed. It was, however, extremely useful to the Reader Services team members at IALS, who would like to provide a level of service and support reasonably consistent with that available in the other local academic libraries used by our students and teaching/research staff. A programme of further development of our current services is in progress. 